\title{
Un acercamiento al régimen tributario de las cooperativas no agropecuarias en Cuba. Propuestas para su perfeccionamiento
} An approach to taxation of non-agricultural cooperatives in Cuba. Proposals for improvement

\author{
Orestes Rodríguez Musa ${ }^{1}$ \\ Universidad de Pinar del Rio (Cuba) \\ Orisel Hernández Aguilar² \\ Universidad de Pinar del Rio (Cuba) \\ Jorge Luis Dueñas Bejerano ${ }^{3}$ \\ Abogado
}

Sumario: I. Introducción. II. Consideraciones teóricas en torno al régimen de tributación de las cooperativas. III. La regulación jurídica de la tributación del sector cooperativo en Cuba. IV. El actual régimen de tributación de las cooperativas no agropecuarias. V. Propuestas para el perfeccionamiento del régimen de tributación de las cooperativas. VI. A modo de conclusiones. VII. Bibliografía.

Summary: I. Introduction. II. Theoretical considerations about the taxation of cooperatives. III. Legal regulation of the taxation of the cooperatives in Cuba. IV. The current taxation of non-agricultural cooperatives. V. Proposals for improving the taxation of cooperativas. VI. By way of conclusion. VII. Bibliography.

Resumen: Este artículo parte de un examen de algunos elementos generales en torno al régimen de tributación de las cooperativas para, seguidamente, centrarse en la regulación legal de la tributación en Cuba, con especial

1 Máster en Derecho Constitucional y Administrativo, Profesor de Derecho Constitucional y Derecho de Cooperativas, Departamento de Derecho, Facultad de Ciencias Sociales y Humanísticas, Universidad de Pinar del Río, Cuba. E-mail: musa@upr.edu.cu

2 Máster en Derecho Constitucional y Administrativo, Profesora de Historia General del Estado y el Derecho y Derecho Romano, Departamento de Derecho, Facultad de Ciencias Sociales y Humanísticas, Universidad de Pinar del Río, Cuba. E-mail: oriselha@ upr.edu.cu

3 Licenciado en Derecho y Abogado de la Organización Nacional de Bufetes Colectivos, Pinar del Río, Cuba. 
referencia al tratamiento del sector cooperativo. Estos análisis permitirán desarrollar una valoración integral de cómo se ha desarrollado el régimen tributario de las cooperativas no agropecuarias en el país, a fin de poder perfilar propuestas para su perfeccionamiento.

Palabras clave: cooperativa, tributos y Derecho.

Abstract: This article is a review of some general elements about the taxation system of cooperatives, to then focus on the legal regulation of taxation in Cuba with special reference to the treatment of the cooperative sector. These analyzes allow us to develop a comprehensive assessment of how developed the taxation of non-agricultural cooperatives in Cuba, in order to outline proposals for their improvement.

Key words: cooperative, taxes and Law. 


\section{Introducción}

Desde la aprobación por el VI Congreso del Partido Comunista de Cuba ${ }^{4}$ de los Lineamientos de la Política Económica y Social del Partido y la Revolución ${ }^{5}$ —documento que contienen las directrices para el perfeccionamiento del modelo socioeconómico cubano- se han desarrollado importantes transformaciones en la Isla. Al amparo del título de "LAS COOPERATIVAS», que abarca del lineamiento 25 al 29, se reconoce a estas entidades como parte de un nuevo «MODELO DE GESTIÓN ECONÓMICA» con el que el país se propone elevar la productividad del trabajo ${ }^{6}$.

En fecha 11 de diciembre de 2012 la Gaceta Oficial de la República de Cuba, en una edición extraordinaria, publicó un conjunto de normas, de carácter experimental, que configuran el marco jurídico para las cooperativas no agropecuarias (en lo adelante CNA). Se trata de dos Decretos-Leyes, un Decreto y dos Resoluciones. El Decreto-Ley N. ${ }^{\circ} 305$ «De las cooperativas no agropecuarias» ${ }^{7}$ se ocupa de sentar «las normas que regulan la constitución, funcionamiento y extinción de cooperativas en sectores no agropecuarios de la economía nacional» ${ }^{8}$. El Decreto-Ley N. ${ }^{\circ} 306$ «Del régimen especial de seguridad social de los socios de las cooperativas no agropecuarias» ${ }^{9}$ como su nombre indica «establece un régimen especial de seguridad social dirigido a la protección de los cooperativistas asociados en cooperativas no agropecuarias» ${ }^{10}$. El Decreto N. ${ }^{\circ} 309$ del Consejo de Ministros dis-

4 Vid. Lineamientos de la Política Económica y Social del Partido y la Revolución, aprobados el 18 de abril de 2012, consultados en http://www.prensa-latina.cu/Dossiers/ Lineamientos VICongresoPCC.pdf

5 En lo adelante Lineamientos.

6 Hasta ese momento las regulaciones con que el ordenamiento jurídico cubano contaba en materia de cooperativas se limitaban a admitir las cooperativas en el sector agropecuario. Las normas que operaban eran, esencialmente: con carácter general el artículo 20 de la Constitución de la República de 1976 (actualizada); con carácter supletorio los artículos del 145 al 149 del Código Civil, Ley 59 de 16 de julio de 1987 (en lo adelante (C) y con carácter especial la Ley de Cooperativas de Producción Agropecuaria y de Créditos y Servicios, Ley 95 del 2 de noviembre de 2002 (en lo adelante LCPACS) y el Decreto Ley 142 de 20 de septiembre de 1993, Sobre las Unidades Básicas de Producción Cooperativa.

7 En lo adelante DL305/2012.

8 Art. 1, Decreto-Ley N. ${ }^{\circ} 305$ «De las cooperativas no agropecuarias», Gaceta Oficial N. ${ }^{\circ} 053$ Extraordinaria de 11 de diciembre de 2012, MINJUS, La Habana, 2012, p. 249.

9 En lo adelante DL 306/2012.

10 Art. 1, Decreto-Ley N. ${ }^{\circ} 306$ «Del régimen especial de seguridad social de los socios de las cooperativas no agropecuarias», Gaceta Oficial N. ${ }^{\circ} 053$ Extraordinaria de 11 
pone el «Reglamento de las cooperativas no agropecuarias de primer grado» ${ }^{11}$. La Resolución N. ${ }^{\circ} 570$ del Ministerio de Economía y Planificación pone en vigor el procedimiento de licitación respecto a los bienes de un establecimiento estatal para su gestión por las cooperativas no agropecuarias y la Resolución N. ${ }^{\circ} 427$ del Ministerio de Finanzas y Pre$\operatorname{cios}^{12}$ ordena las particularidades relativas a la materia tributaria, precios, normas contables, y mecanismos de financiación.

La previsión misma del carácter experimental de estas normas advierte que se trata de una práctica sometida a perfeccionamiento y, por tanto, que son importantes los estudios que sobre ella se realicen, a fin de que la legislación que definitivamente se adopte para regularla, supere las dificultades que durante el experimento se presenten. Al respecto, es válido resaltar que el VII Congreso del Partido Comunista de Cuba recién ha aprobado el proyecto de «Conceptualización del Modelo Económico y Social Cubano de Desarrollo Socialista», y el «Plan Nacional de Desarrollo Económico y Social hasta 2030: propuesta de visión de la Nación, Ejes y Sectores Estratégicos», documentos que reiteran la voluntad de apostar por el desarrollo de las cooperativas.

Estos documentos se han hecho acompañar por un conjunto de nuevas disposiciones normativas de carácter tributario, contenidas en la Gaceta Oficial N. ${ }^{\circ} 12$ Extraordinaria de 13 de abril de 2016, entre las que destacan, a los efectos de este estudio, aquellas asociadas al tratamiento fiscal de las CNA. Teniendo en cuenta estas novedades y dada la importancia de la materia tributaria para la feliz evolución del sector cooperativo en cualquier contexto, conviene valorar cómo se ha desarrollado este régimen en Cuba a fin de perfilar propuestas para su perfeccionamiento, no sin antes sentar una base teórica suficiente para sustentarlas.

\section{Consideraciones teóricas en torno al régimen de tributación de las cooperativas}

Las cooperativas tienen una naturaleza compleja, que no coincide con ninguna de las figuras jurídicas tradicionales. Para explicar lo anterior se ha estructurado la teoría del "acto cooperativo», de factura latinoamericana y que tiene entre sus principales exponentes a SALINAS Puente en México, Bulgarelli en Brasil y a Cracogna en Argentina, ade-

de diciembre de 2012, MINJUS, La Habana, 2012.

11 En lo adelante D309/2012.

12 En lo adelante R 427/2012. 
más de que se ha concretado en la Ley Marco para las Cooperativas de América Latina ${ }^{13}$ y en la legislación de al menos 14 países de la región ${ }^{14}$.

Este acto constituye el medio o instrumento principal para la realización práctica de la razón de ser de la cooperativa. SALINAS PUENTE se refiere a él como «el supuesto jurídico, ausente de lucro y de intermediación, que realiza la cooperativa en cumplimiento de un fin preponderantemente económico y de utilidad social» ${ }^{15}$. En la misma dirección explica Cracogna las notas esenciales y consustanciales a estos actos que permiten afirmar que no tienen una naturaleza civil ni comercial ni otra cualquiera, sino una que les es propia y que los distingue dada la propia finalidad de la institución: a) intervención de socio y cooperativa; b) objeto del acto idéntico al objeto de la cooperativa; y c) espíritu de servicio, donde hay un corpus (el objeto material o inmaterial sobre el que versa) y un animus (el espíritu de servicio que informa la relación) ${ }^{16}$.

Por consiguiente, en la cooperativa " el fin no es el lucro, sino el servicio al socio; no es la ganancia, sino la satisfacción de sus necesidades, pues, esas necesidades son las que unieron a los socios para formar la cooperativa y mediante el aporte y esfuerzo mutuo, autoproveerse de su fuente de trabajo, de servicios, de abastecimiento o comercialización de sus productos, según el tipo de cooperativa» ${ }^{17}$. Por ejemplo, en una cooperativa de trabajo, la actividad económica que se desarrolla (V. gr.: gastronomía, trasporte, gestoría de alojamiento, etc.)

13 «Artículo 7: Son actos cooperativos los realizados entre las cooperativas y sus socios o por las cooperativas entre sí en cumplimiento de su objetivo social y quedan sometidos al Derecho Cooperativo» ACl-AméRICAS: Ley Marco para las Cooperativas de América Latina, San José, 2008, en www.aciamericas.coop, consultada 18 de diciembre de 2009.

14 V. gr.: Brasil: (Ley No. 5764 del 16.12.71); Argentina: (Ley 20337 del 15.05.73); Uruguay: (Ley 15645 del 9.10.84); Honduras: (Decreto No. 65-87 del 20.05.87); Colombia: (Ley 79 del 23.12.88); México: (Ley del 03.08.94); Paraguay: (Ley 438 del 21.10.94). Para mayor información Vid. García Müller, A.: Derecho Cooperativo y de la Economía Social y Solidaria, Asociación Iberoamericana de Derecho Cooperativo, Mutual y de la Economía Social y Solidaria, Mérida, 2015, pp. 19-31 y TORRES Morales, C: Reconocimiento del acto cooperativo en la legislación peruana, consultado en http://www. teleley.com/articulos/art_221013a.pdf, el 15 de mayo de 2016.

15 Salinas Puente, A.: Derecho Cooperativo, Ed. Cooperativismo, México, 1954, p. 2.

16 Cracogna, D.: Estudios de Derecho Cooperativo, INTERCOOP Ed. Cooperativa Ltda., Buenos Aires, 1986, p. 21.

17 NARANjo Mena, C: "La naturaleza jurídica de la cooperativa y el acto cooperativo», SIBULE, Asesores Legales, 2014, recuperado de http://www.sibule.com/\#!La-NaturalezaJur\%C3\%ADdica-de-la-Cooperativa-y-el-Acto-Cooperativo/c104m/1, el 15 de mayo de 2016. 
es solo un medio que sirve al propósito superior de satisfacer la necesidad de un empleo digno y óptimamente retribuido a sus asociados ${ }^{18}$. La actividad empresarial no es un fin en sí mismo, sino un medio para la consecución de determinado objetivo social. El capital sirve al hombre y no a la inversa.

Por tanto, es el acto cooperativo la piedra angular para sostener la naturaleza peculiar de las relaciones sociales que resultan al interior de lo que llama BuLGaReLli ${ }^{19}$ el "círculo cerrado» de estas formas asociativas, es decir, entre ella y sus asociados, y también en el ámbito cooperativo, o sea, entre entidades de este tipo que colaboran unas con las otras en cumplimiento de su objetivo social. ${ }^{20}$

El tratamiento tributario que se les aplique a las cooperativas debe estar en correspondencia con su naturaleza jurídica. Con base en esta misma lógica, la cooperativa requiere de un tratamiento tributario propio que no violente su esencia. Ella «no tiene materia gravada porque constituye la herramienta de que se vale el socio para hacer su actividad económica, no tiene lucro autónomo, un beneficio que pueda ser gravado. Si se le gravara se estaría disminuyendo su capital o bien se trasladaría a los asociados y, en definitiva, estos estarían pa-

18 De similar manera ocurre en las cooperativas de consumo o provisión, donde «la cooperativa no produce una renta propia porque cuando realiza su actividad cobra el servicio a un precio que se estima conforme con el mercado. Pero ese precio es provisional, sea que la cooperativa distribuya artículos, por ejemplo, una cooperativa de consumo o de provisión, sea que la cooperativa comercialice la producción de sus socios. En el primer caso la cooperativa le cobra demás al asociado cuando retira artículos de consumo, para cubrir sus gastos. En el otro caso le retiene una suma al momento de pagarle su producción, también para cubrir sus gastos, porque no sabe exactamente cuáles son sus costos. Cobra pues un precio aproximado al del mercado, y al final del ejercicio, se efectúan el balance y estado de resultados, entonces aparece la verdadera y definitiva determinación del precio de servicio. Allí se determina si lo que se le cobró al asociado en la cooperativa de consumo es demás respecto del precio que debió habérsele cobrado, y en la cooperativa de comercialización, si lo que se le pagó es menos de lo que debió habérsele pagado. Entonces se hace un ajuste que resulta de la distribución del excedente por vía del retorno. En consecuencia, en la cooperativa no quedan ganancia, no quedan rentas, no quedan beneficios porque lo que se cobró demás en la de consumo o lo que se pagó de menos en la de comercialización, se devuelve al asociado por vía de la prorrata del retorno». CRACognA, D.: Problemas actuales del Derecho Cooperativo, INTERCOOP Ed. Cooperativa Ltda., Buenos Aires, 1992, p. 171.

19 Distinguió la existencia de dos tipos de relaciones en las cooperativas: una derivada de los actos que la cooperativa practica con sus asociados en cumplimiento de su objeto social, y otra derivada de los actos que realiza con terceros no socios. A los primeros, que se realizan de manera interna, en un "círculo cerrado» los llamó actos cooperativos. Vid. Bulgarelul, W.: Elaboração do Direito Cooperativo, Ed. Atlas S.A., São Paolo, 1967, p. 107.

20 Vid. ACl: Ley Marco para..., ob. cit., artículos 7. 
gando dos veces, una en su propio balance impositivo y otra en el de la cooperativa» ${ }^{21}$, habría una doble imposición.

Por tanto, una política pública más científica, no confunde el mero «Régimen de Privilegios» o «Promocional» previsto por muchos Estados para la institución, con las exenciones o inaplicaciones que sus actos típicos merecen con respecto a algunos tributos. Esta posición cuenta con un importante apoyo en la doctrina cooperativa como se verá a continuación.

Siguiendo a PASTORINO, debe admitirse que no hay «hecho imponible en la operación que realiza la cooperativa con su asociado sobre el que pueda recaer el impuesto al valor agregado, y cuando el Fisco lo cobra, está sometiendo a los cooperadores a una doble tributación: pagan los asociados cuando en forma de cooperativa van al mercado, y pagan nuevamente cuando se distribuyen la misma mercadería que trajeron del mercado. De acuerdo con lo visto, sólo hay un contribuyente: los asociados reunidos en cooperativa; y un único hecho imponible: la compra que hacen esos asociados reunidos en

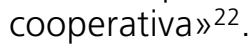

Tampoco en estos casos, advierte CRACOGNA, «hay materia gravable con impuesto a la renta porque lo que constituye la diferencia entre el costo y el precio del servicio va a parar a los asociados, que son los que generaron esa diferencia con su respectiva operatoria; de donde se sigue que gravar a las cooperativas con el impuesto a la renta es improcedente ${ }^{23}$. Al respecto sostiene TORRES MORALES que «El mismo criterio debería aplicarse para el caso de las cooperativas de trabajadores, pues el ingreso que obtiene la cooperativa y que es pagado por «terceros» no le pertenece a la cooperativa, sino que ésta debe entregarlo a cada uno de los socios en proporción al trabajo desarrollado» ${ }^{24}$.

Las cooperativas de consumo, en particular, «no pueden estar sujetas al impuesto a las transacciones o a las ventas pues entre la cooperativa y el socio no llega a producirse ninguna transacción, ni venta, sino una simple distribución. Los socios compran en común utilizando la personalidad jurídica de la cooperativa y luego se distribuyen lo que

21 Cracogna, D: Problemas actuales del..., ob. cit., p.171.

22 PAstorino, R.: Impuesto a las Transacciones Cooperativas, INTERCOOP, Ed. Cooperativa Ltda., Buenos Aires, 1981, p. 79.

23 Cracogna, D.: Problemas actuales del..., ob. cit., p. 172.

24 Torres Morales, C: «Reconocimiento del acto cooperativo en la legislación peruana», consultado en http://www.teleley.com/articulos/art_221013a.pdf, el 15 de mayo de 2016, p. 7. 
ellos han comprado a diferencia de lo que ocurre en el acto de comercio donde, se compra para vender» ${ }^{25}$.

Por último, en lo tocante al Impuesto a las Transferencias, «en vez de declarar su exoneración se concibe que resulte inaplicable para las cooperativas pues ellas, no son intermediarias sino mandatarias o representantes de sus socios. El hecho de que utilicen procedimientos usuales en las empresas mercantiles o contratos de compraventa en ciertos casos, no modifica la realidad misma. La legislación tributaria entonces comienza a ver el fondo del acto cooperativo sin necesidad de caer en la simplista visión de juzgar por las formas» ${ }^{26}$.

Consiguientemente, coincidimos con GARCía MülLER en que «el acto cooperativo no crea base imponible, razón por la cual las cooperativas no son sujetos de impuesto cuando los practican» ${ }^{27}$. De ahí que el tratamiento tributario de la cooperativa deba seguir dos vertientes diferentes, una en cuanto a sus actos comerciales y otra respecto a sus relaciones con los socios que la integran.

\section{La regulación jurídica de la tributación del sector cooperativo en Cuba}

El triunfo de la Revolución «trajo consigo, para la tributación y el Derecho Tributario, un período de franco descenso en nuestro país ${ }^{28}$. Esta situación obedeció a que en Cuba se asumieron los «criterios y teorías desarrolladas por la doctrina socialista del este de Europa contra la tributación en general, y muy especialmente contra la imposición indirecta, que postulaban, esencialmente, el rechazo a la tesis de la imponibilidad tributaria por parte del Estado. Esta teoría socialista propugnó la generación de los fondos públicos a través de la redistribución de las ganancias de las empresas estatales hacia los fines de la satisfacción de las necesidades de la población, renunciando, como principio, al tributo como fuente de recaudación esencial de dichos fondos» 29 .

25 TORRES y TORRES LARA, C.: Derecho Cooperativo. La Teoría del Acto Cooperativo, Ed. Inesla, Lima, 1990, p. 49, citado por TORRES Morales, C: Reconocimiento del acto..., ob. cit., p. 8.

26 Ibídem, p. 7.

27 García Müller, A.: El acto cooperativo, construcción latinoamericana, recuperado de www.aidcmess.com.ar, el 12 de marzo de 2016.

28 SIMÓN, L.: "Comentarios a la nueva ley tributaria cubana», en Documentos. No. 10, Instituto de Estudios Fiscales, 2014, p. 8.

29 VALDÉs, E.: La Imposición sobre el Consumo en Cuba. Valoración crítica y propuesta de reforma, Ed. Publicaciones de la Universidad de Alicante, España 2002, p. 207. 
Como parte de las transformaciones que trajo aparejada la crisis de los años 90, tras la caída del campo socialista de Europa del Este, se comenzaron a dar cambios importantes en materia económica en el país. «La apertura de la economía cubana a nuevas relaciones, provocó que el tema tributario fuera reevaluado, por su importancia en la recaudación de fondos públicos para la satisfacción de necesidades sociales» ${ }^{30}$. Una primera particularidad de la regulación legal de la tributación que se hace en Cuba a partir de entonces es la inexistencia de un claro respaldo constitucional para ella. La Carta Magna, tanto en su versión original de $1976^{31}$ como luego de las reformas de $1992^{32}$ y $2002^{33}$, es omisa sobre el tema en cuestión, el cual debió haber sido regulado en el Capítulo VII que se ocupa de los Deberes, Derechos y Garantías Fundamentales. En busca de una solución se ha pretendido enmendar la situación por medio de una interpretación extensiva de los preceptos de la ley suprema cubana. Siendo así que, se ha procurado derivar el deber de contribuir del artículo 34, que apunta que los extranjeros residentes en el territorio nacional se equiparan a los cubanos en el deber de contribuir a los gastos públicos. Esta interpretación es bastante amplia, pues no solo ha servido para entender gravados los actos de las personas naturales nacionales, sino que además sus efectos han alcanzado a las personas jurídicas colectivas, incluyendo las cooperativas.

Con la entrada en vigor de la Ley 73 «Del Sistema Tributario» de 1994 en Cuba se retoma el camino del cobro de los tributos como forma de ingreso al erario público. Esta norma «implementó en el país un conjunto de tributos, armónicamente estructurados, con el objetivo de gravar las tres posibles fuentes de capacidad económica: la renta, el patrimonio y el consumo» ${ }^{34}$.

Bajo los dictados de esta Ley, algunas de las cooperativas entonces existentes, que se limitaban al sector agropecuario -entiéndase Cooperativas de Producción Agropecuaria (CPA), Cooperativas de Créditos y Servicios (CCS) y las Unidades Básicas de Producción Coopera-

30 SIMÓN, L.: Comentarios a la..., ob. cit., p. 10.

31 Constitución de la República de Cuba. Gaceta Oficial de la República de Cuba Edición Especial de 24 de febrero de 1976.

32 Constitución de la República de Cuba, reformada por la Ley de Reforma Constitucional. Gaceta Oficial de la República de Cuba N. 9 Extraordinaria de 13 de julio de 1992.

33 Constitución de la República de Cuba, reformada por la Ley de Reforma Constitucional. Gaceta Oficial de la República de Cuba N. ${ }^{\circ} 10$ Extraordinaria de 16 de julio de 2002.

34 VALDÉs, E.: ob. cit., p.19. 
tiva (UBPC) - gozaron de un régimen especial tributario establecido por la Disposición Final Cuarta de la referida ley.

Respecto al impuesto por la utilización de la fuerza de trabajo, el inciso a) de la aludida disposición final, previó una exención para las Cooperativas de Producción Agropecuaria y las Unidades Básicas de Producción Cooperativa, en los casos de sus miembros permanentes y contratados autorizados y estudiantes ${ }^{35}$. Sobre esta regulación hay que apuntar que el legislador, que definió en el artículo 45 como el hecho imponible del tributo en cuestión a «la utilización de fuerza de trabajo asalariada», confunde a los miembros permanentes de las cooperativas con trabajadores asalariados. Independientemente de este error, no se puede pasar por alto que al convertirlas en las únicas personas jurídicas excluidas expresamente del pago, ascendiente al $25 \%$ de la totalidad de los salarios, sueldos, gratificaciones y demás remuneraciones ${ }^{36}$, se les estaba confiriendo a las entidades aludidas un estatus privilegiado.

Asimismo, en el inciso b) se dispuso la exención del pago del impuesto sobre utilidades, con arreglo a las disposiciones del Ministerio de Finanzas y Precios, para aquellas Cooperativas de Producción Agropecuaria y Unidades Básicas de Producción Cooperativa de menores ingresos, en proporción con los ingresos reales percápita a recibir por sus miembros. Esta es claramente una medida de estímulo para el desarrollo de tales entidades pues, de los sujetos sometidos al régimen tributario general dispuesto en la Ley No. 73, solo ellas resultan liberadas de tributar el $35 \%$ de las utilidades netas disponibles ${ }^{37}$.

Para los miembros de las Cooperativas de Producción Agropecuaria y las Unidades Básicas de Producción Cooperativa se normó en el inciso c) una deducción en el impuesto sobre ingresos personales para aquellos ingresos obtenidos en función de las utilidades que reciban de las referidas organizaciones. La medida tiene significación positiva, en tanto deviene en una garantía exclusiva de los cooperativistas a quienes les asegura que las retribuciones que reciban por ostentar tal condición no están afectadas por el citado impuesto. Esta decisión puede ser mejor comprendida si se asume, como señala Pérez InCLÁn, que la existencia del tributo aludido está «determinada por la regulación y control de los ingresos de sectores específicos, que obtienen ni-

35 Se refiere a los estudiantes que se movilizan para actividades productivas y por cuyo trabajo las cooperativas erogan el equivalente al salario que correspondería a un obrero contratado por igual desempeño.

36 Vid. Artículos 46 y 47, Ley 73 «Del Sistema Tributario».

37 Vid. Artículo 14, Ley 73 «Del Sistema Tributario». 
veles de redistribución superiores a la media de quienes laboran en el sector estatal» ${ }^{38}$.

Por último, en el inciso d) se contempló la posibilidad de establecer adicionalmente bonificaciones según la característica de cada territorio, cultivo u organización, con el fin de propiciar por esta vía un estímulo adicional a la producción. Habida cuenta de la sensibilidad que puede tener la actividad agrícola en determinadas zonas del territorio nacional y la que se asocia de algunos cultivos particulares, se ha de entender que esta es una previsión claramente enfocada a velar por la justicia tributaria, con un claro y especial interés por hacerlo en favor del sector cooperativo.

Por tanto, queda evidenciado que con la Ley 73 «Del Sistema Tributario» de 1994 en Cuba, las cooperativas estuvieron bajo un tratamiento tributario privilegiado.

\section{El régimen de tributación de las cooperativas no agropecuarias}

El desarrollo de las cooperativas no agropecuarias (CNA) comenzó casi paralelo a la promulgación de la Ley 113 «Del Sistema Tributario» de $2012^{39}$, por lo cual su régimen de tributación se concibió en lo fundamental en torno a las disposiciones previstas en esta norma y la Resolución 427 del Ministerio de Finanzas y Precios de 2012. Recientemente, la Resolución 427/2012 fue derogada por la Resolución 124 del propio ministerio ${ }^{40}$, de fecha 13 de abril de $2016^{41}$, que introduce algunas modificaciones en el tratamiento fiscal previamente formulado para las CNA.

Por ende, la exposición que sigue se detendrá en los dos momentos fundamentales que, al respecto de la tributación en cuba por parte de las CNA se pueden delimitar, el primero, con la publicación de la Gaceta Oficial N. ${ }^{\circ} 053$ Extraordinaria de 11 de diciembre de 2012, y el segundo que se abre con la Gaceta Oficial N. ${ }^{\circ} 12$ Extraordinaria de 13 de abril de 2016.

38 Pérez InCLÁn, C.: «Sistema Tributario Cubano», en Colectivo de Autores: Apuntes de Derecho Financiero Cubano, Editorial Félix Varela, La Habana, 2007, p. 287.

39 Gaceta Oficial N. 053 Ordinaria de 21 de noviembre de 2012, MINJUS, La Habana, 2012.

40 En lo adelante R124/2016. 2016.

41 Gaceta Oficial N. ${ }^{\circ} 12$ Extraordinaria de 13 de abril de 2016, MINJUS, La Habana, 
Pero, antes de realizar este análisis, vale advertir en cuanto a la naturaleza jurídica atribuida a las CNA que «el legislador utilizó una fórmula muy genérica al calificarla como organización, por lo que no la reconoce expresamente ni como una sociedad ni como una asociación. Sin embargo, otros artículos del texto legal nos conducen a pensar en la posibilidad de concebir a la cooperativa como una sociedad mercantil... ${ }^{42}$.

Tanto el DL305/2012 como el D309/2012, no son consecuentes con la naturaleza jurídica de la institución objeto de estudio. En el artículo 2 del DL305/2012 se plasma que «el objetivo general [de las cooperativas] es la producción de bienes y la prestación de servicios» y el D309/2012 comprende como objeto social de las cooperativas en su artículo 14 «...las producciones, prestación de servicios o la actividad de comercialización...». De ello se colige que no se ha ponderado en su justa medida el servicio que la cooperativa debe prestar a sus miembros $^{43}$ y que constituye su objetivo social principal.

Ante estas ambigüedades, también las deformaciones de la práctica jurídica y social la han acercado a las sociedades mercantiles lucrativas $^{44}$, por lo que la generación de empleo por las CNA a sus asociados ha resultado, cuando menos, secundario, en tanto el principal propósito ha sido encontrar en la empresa cooperativa un medio para obtener beneficios económicos a través de la actividad mercantil y, en consecuencia, se ha empleado un régimen tributario que se orienta hacia la distribución social indirecta de los beneficios económicos que de estas cooperativas se obtienen.

42 Mesa Tejeda, N.T.: "Reflexiones críticas en torno a la regulación de las cooperativas no agropecuaria en Cuba», en Boletín de la Asociación Internacional de Derecho Cooperativo, No. 48, Universidad de Deusto, 2014, p. 231.

${ }^{43}$ Lo anterior se constata al verificar los objetos sociales declarados en las CNA constituidas en la provincia de Pinar del Río, como es el caso de «La Casa Colonial» y el "Café Pinar», las que reconocen como objeto social, en el primer caso, "Ofertar una amplia variedad de alimentos elaborados, que podrán ser producidos centralizadamente y producidos en la unidad o procesados en el propio establecimiento.... y, y en el segundo «...prestar servicios gastronómicos y de recreación, arrendar local y espacios para eventos festivos...»; los que constituyen actos comerciales de la cooperativa con terceros pero donde no se reflejan las necesidades a satisfacer por la cooperativa a sus asociados. Vid. HeRnÁNDEZ, O.: Las cooperativas no agropecuarias en Pinar del Río. Una aproximación al enfoque de género en su funcionamiento, en Revista de Estudios Cooperativos N. ${ }^{\circ}$ 6, Universidad de Deusto, 2015, pp. 159-179.

44 V. gr.: centralización y control administrativos del proceso para su constitución, durante su funcionamiento, y para su disolución, vinculado a su vez a la brusquedad de ofrecerla como única solución ante el abandono de la función empleadora de la Administración y a la ausencia de otra alternativa para que los particulares operen a través de entidades económicas con la personalidad jurídica necesaria para realizar actividades de comercio. 
Desde la publicación de la Gaceta Oficial N. 053 Extraordinaria de 11 de diciembre de 2012

Las CNA son consideradas como una organización ${ }^{45}$ con personalidad jurídica y patrimonio propio, lo que las hace ser sujetos de derechos y obligaciones, encontrándose dentro de estas últimas el deber de contribuir $^{46}$ que por ley corresponde al ejercicio de determinadas actividades económicas o por la tenencia y disposición sobre los bienes o recursos, elementos éstos considerados desde el Derecho Financiero como hecho imponible ${ }^{47}$. Los tributos más significativos que gravan a las CNA son el Impuesto sobre Utilidades, el Impuesto sobre Ventas, el Impuesto sobre los Servicios, el Impuesto sobre la Utilización de la Fuerza de Trabajo, la Contribución a la Seguridad Social y la Contribución Territorial para el Desarrollo Local.

Las CNA están exentas del pago de impuestos en los tres primeros meses $^{48}$ desde el inicio de su actividad, lo que si bien puede entenderse como un incentivo para sus socios promotores resulta insuficiente, dada su corta duración.

En cuanto a estas exenciones, dada la poca claridad que tiene su previsión normativa, se han generado —-según PINEEIRO HARNECKER-confusiones en las oficinas municipales de la Oficina Nacional de Administración Tributaria (ONAT) respecto a la forma en que debe hacerse el cálculo del tiempo, pues «no queda claro si la fecha de comienzo de operaciones es la fecha de registro en la ONAT, la fecha de registro en el Registro Mercantil, la fecha del primer contrato $u$ otro criterio que tenga en cuenta que para algunas actividades como el transporte la construcción y elaboración de alimentos es necesario obtener otras licencias antes de que se pueda comenzar a operar ${ }^{49}$.

Las cooperativas no agropecuarias tienen un tratamiento especial en el Impuesto sobre Utilidades, según lo establecido en los artículos

45 Artículo 2, Decreto-Ley N. ${ }^{\circ} 305$ «De las cooperativas no agropecuarias», Gaceta Oficial N. 053 Extraordinaria de 11 de diciembre de 2012, MINJUS, La Habana, 2012.

46 Vid. Artículo 5, inciso x), Ley 113/2012, «Del Sistema Tributario».

47 Artículo 5, inciso o), Ley 113/2012, "Del Sistema Tributario».

48 Resuelvo Undécimo: Se eximen del pago de las obligaciones tributarias por concepto de impuestos sobre Utilidades, sobre las Ventas, sobre los Servicios y por la Utilización de la Fuerza de Trabajo, correspondientes a los primeros tres (3) meses de operaciones, a las cooperativas no agropecuarias que se inicien en el ejercicio de la actividad.

Resolución N. ${ }^{\circ} 427$ del Ministerio de Finanzas y Precios, Gaceta Oficial N. ${ }^{\circ} 053$ Extraordinaria de 11 de diciembre de 2012, MINJUS, La Habana, 2012.

49 PIÑEIRO, C.: Diagnóstico preliminar de las cooperativas no agropecuarias en La Habana, Cuba, mayo de 2014, p. 176. 
del 106 al 108 de la Ley 113/2012. La particularidad está dada porque el pago se realiza de acuerdo con lo que se denomina «utilidad fiscal per cápita», la cual se determina a partir de descontar de los ingresos anuales obtenidos los siguientes conceptos: mínimo exento por cada miembro (que asciende a diez mil pesos cubanos ${ }^{50}$ ); los gastos asociados a la actividad en los límites y condiciones que establezca el Ministro de Finanzas y Precios; los tributos pagados ${ }^{51}$.

A ello se suma que, en virtud del Resuelvo Séptimo de la Resolución 427/2012, al total de los ingresos obtenidos en el año fiscal se le deducirán el arrendamiento de los bienes muebles e inmuebles de los locales estatales en los que asuman reparaciones; una retribución por socio, consistente en el salario medio del territorio donde esté establecida u opere la cooperativa; y los montos destinados a la creación de las reservas para cubrir contingencias. Además, los gastos asociados a la actividad se contabilizarán como tales en su totalidad, no teniendo que justificar el $40 \%$ de ellos.

Estas previsiones son de suma importancia si bien tenemos en cuenta que establecen un régimen progresivo de tributación, que nace de pagar el impuesto sobre las utilidades, con base en las utilidades fiscales percápitas. De lo anterior, y de la lectura de la propia Ley $113 / 2012$, se evidencia que el tratamiento a las CNA en cuanto a este tipo de impuesto es más benévolo que el tipo impositivo general que establece la Ley, del 35\%, para el resto de las personas jurídicas.

Además, debe apuntarse que, a fin de evitar la doble imposición fiscal la Ley $113 / 2012$ en su artículo 18, inciso d), tuvo a bien exonerar del pago del Impuesto sobre los Ingresos Personales a los ingresos que los miembros de cooperativas obtengan de estas, cuando las mismas tributan el Impuesto sobre Utilidades en la modalidad de utilidad per cápita.

El Impuesto sobre las Ventas grava a los bienes destinados al uso y consumo que sean objeto de compraventa, importados o producidos, total o parcialmente en Cuba52. Este impuesto tiene un tipo impositivo del $2 \%$ común para las ventas realizadas por las personas jurídicas autorizadas a comercializar bienes de forma mayorista, incluidas las $\mathrm{CNA}^{53}$. Solo están exentas del pago de este impuesto las CNA que comercialicen a la población productos agropecuarios ${ }^{54}$.

50 Artículo 107, Ley 113/2012, «Del Sistema Tributario».

51 Artículo 108, Ley 113/2012, «Del Sistema Tributario».

52 Artículo 132, Ley 113/2012, "Del Sistema Tributario».

53 Artículo 137, Ley 113/2012, «Del Sistema Tributario».

54 Resuelvo Segundo, Resolución N. ${ }^{\circ}$ 427/2012 del Ministerio de Finanzas y Precios. 
Son sujeto del Impuesto sobre los Servicios, las CNA que desarrollen actividades relativas a servicios telefónicos, de comunicaciones, de transmisión de energía eléctrica, agua, gas, alcantarillado, transporte de carga y pasajeros, gastronómicos, de alojamiento, arrendamiento y recreación, así como otros servicios que se presten en el territorio nacional $^{55}$. El tipo impositivo que se establece al respecto es del diez por ciento y la única posibilidad de eximirse del pago del mismo está asociada a la prestación de servicios destinados a la exportación ${ }^{56}$.

El Impuesto por la Utilización de la Fuerza del Trabajo, en caso que contraten más de 5 trabajadores, tiene como base imponible el total de las remuneraciones derivadas de relaciones laborales ${ }^{57}$. La Ley 113/2012 establece unos tipos impositivos decrecientes ${ }^{58}$ que comienzan por el $20 \%$ para el primera año, $15 \%$ para el segundo, $12 \%$ tercero, $10 \%$ para cuarto y $5 \%$ del quinto en adelante.

La Contribución a la Seguridad Social que regula también la Ley 113/2012, tiene como hecho imponible concertar el empleo de fuerza de trabajo remunerada ${ }^{59}$. Para las CNA se previó en el Resuelvo Quinto de la Resolución 427/2012 un régimen especial establecido en el Decreto-Ley No. 306/2012, para el caso de los socios de las CNA. La fijada por el DL 360/2012 es del 20 por ciento de la base de contribución seleccionada dentro de una escala progresiva regulada en su artículo 17.

Por último, la Contribución Territorial para el Desarrollo Local afecta a las CNA en una cuantía a determinar conforme al tipo impositivo que se disponga en la Ley Anual del Presupuesto ${ }^{60}$ sobre una base imponible «constituida por la totalidad de los ingresos provenientes de la venta de bienes y la prestación de servicios, atribuibles a cada establecimiento o a la propia empresa, sociedad o cooperativa cuando genere por sí misma estos ingresos» ${ }^{61}$.

Por tanto, el régimen tributario de las CNA previamente descrito ha sido, desde un inicio especial y contentivo de un trato más beneficioso que el general: Pagan un $5 \%$ menos en la contribución a la seguridad social, es decir, de un $20 \%$ en lugar del $25 \%$ que pagan los trabajadores por cuenta propia; en la escala del impuesto sobre utilidades que va

55 Artículo 147, Ley 113/2012, «Del Sistema Tributario».

56 Artículo 153, Ley 113/2012, «Del Sistema Tributario».

57 Artículos 228 y 229, Ley 113/2012, «Del Sistema Tributario».

58 MARTín, L.: "Las cooperativas no agropecuarias en Cuba», en REVESCO, N. ${ }^{\circ} 115$-Segundo Cuatrimestre, 2014, p. 155.

59 Artículo 286, Ley 113/2012, «Del Sistema Tributario».

60 Artículo 309, Ley 113/2012, «Del Sistema Tributario».

61 Artículo 308, Ley 113/2012, «Del Sistema Tributario». 
del 10 al $45 \%$ en lugar del 15 y hasta el 50\% para los trabajadores por cuenta propia; también ellas podrán deducir del impuesto sobre las utilidades del $100 \%$ de los gastos (justificando solo el $60 \%$ ); y una exención per cápita igual al salario medio de la provincia multiplicado por el número de miembros de la cooperativa. A lo anterior se suma que se les eximió del pago de todos estos impuestos por los primeros tres meses de operaciones ${ }^{62}$.

\section{A partir de la publicación de la Gaceta Oficial N. 12 Extraordinaria} de 13 de abril de 2016

Una de las primeras variaciones que se introducen con la R124/2016 es la ampliación del término de exención tributaria para las CNA. Esto está en consonancia con el reconocimiento de que, dado lo demorado de los trámites de constitución, resultaba que en la práctica las CNA llegaron a no disfrutaran de esta exención fiscal ${ }^{63}$. Según la normativa en cuestión se les exime de los pagos «correspondientes al mes en que formalizan su inscripción en el Registro de Contribuyentes de la Oficina Nacional de Administración Tributaria, y a los seis meses siguientes a ese período, a las cooperativas no agropecuarias que se inicien en el ejercicio de la actividad ${ }^{64}$.

En cuanto a su redacción la R124/2016 supera a su predecesora en cuanto esclarece y puntualiza algunas cuestiones que la anterior resolución no preveía correctamente: incluye a la olvidada Contribución Territorial para el Desarrollo Local en el Resuelvo Primero y supera la limitación del anterior Resuelvo Segundo que, al referirse a los impuestos sobre las Ventas y sobre los Servicio, atribuía la previsión de su tipo impositivo a la Ley del Presupuesto de 2013. Ahora la norma vigente dispone que el tipo impositivo sea establecido por la Ley Anual del Presupuesto del Estado o por la disposición complementaria que a los efectos de este Impuesto se disponga.

En el Resuelvo Quinto, que se refiere a la Contribución a la Seguridad Social se ha introducido un párrafo que esclarece que, "Cuando las cooperativas no agropecuarias contraten personal asalariado, pagan la Contribución a la Seguridad Social de conformidad con lo esta-

62 PIÑEIRO, C.: Diagnóstico preliminar de las cooperativas no agropecuarias en La Habana, Cuba, mayo de 2014, p. 176.

63 Vid. TRISTÁ, G.: Cooperativas no Agropecuarias, Comisión de Implementación de los Lineamientos, Conferencia ofrecida en septiembre de 2015.

64 Undécimo Resuelvo, Resolución 124/2016. 
blecido en la Ley Anual del Presupuesto del Estado o en la disposición complementaria que a los efectos de este tributo se disponga». Esta situación había sido obviada en la Resolución 427/2012 que se limitaba a aludir a los socios de las CNA.

En cuanto al Impuesto sobre Utilidades la R124/2016 incluye en su Resuelvo Séptimo una deducción de los gastos por contratación de servicios a terceros hasta el límite del cincuenta por ciento del total de los gastos. Corresponde al Ministerio de Finanzas y Precios, previa solicitud y fundamentación que realice el organismo u órgano de relación de la cooperativa no agropecuaria, establecer otro rango, según las características y operatoria de la actividad o actividades fundamentales que realice la cooperativa.

También en lo relativo a este impuesto, según el nuevo Resuelvo Octavo, a las CNA de servicios gastronómicos personales y técnicos de uso doméstico, para cuyos productos o servicios se aprueben precios máximos, por participar en programas priorizados o en los que resulte de interés estatal, en el pago del Impuesto sobre las Utilidades, se les aplicará una bonificación de hasta el 10\%.

Los cambios introducidos por la R124/2016, como se evidencia, acentúan los beneficios del régimen tributario especial de las CNA. De esta forma se refuerza la voluntad política de favorecer las cooperativas como forma de gestión colectiva y democrática que - como regla - no implica el aprovechamiento de la fuerza de trabajo asalariada, lo cual llegará a ser fomento fiscal cooperativo cuando efectivamente se flexibilice el proceso de constitución.

\section{Propuestas para el perfeccionamiento del régimen de tributación de las cooperativas}

A continuación, se exponen algunos puntos que, a consideración de los autores, que pueden servir de referentes para la implementación del futuro perfeccionamiento del régimen de tributación de las cooperativas no agropecuarias.

Definición uniforme y acertada de la naturaleza jurídica de la cooperativa

Una primera cuestión sería unificar, de forma correcta, la concepción de la naturaleza jurídica de la cooperativa, que presenta una confusión importante en su tratamiento por la legislación y los operadores nacionales. 
En el ordenamiento jurídico cubano se entiende a la cooperativa como una forma de propiedad a partir del 24 de febrero de 1976 con la proclamación del texto constitucional socialista. El artículo 20 de este cuerpo jurídico (reformado en 1992), resalta desde un inicio que «Esta propiedad cooperativa es reconocida por el Estado...». Por su parte, el Código Civil, al ubicar a la cooperativa en su TíTULO II: DERECHO DE PROPIEDAD, CAPÍTULO II: FORMAS DE PROPIEDAD, bajo la denominación de la SECCIÓN TERCERA: Propiedad cooperativa; deja en claro la concepción que asume para explicar la esencia de la figura.

Esta concepción, igualmente presente en la legislación especial agraria, lleva a advertir que «...el modelo jurídico adoptado, está distanciado de la naturaleza social de la institución cooperativa, pues en él se privilegia el componente administrativo-patrimonial, sobre el asociativo...» ${ }^{65}$.

Por su parte, la regulación del DL 305/2012 aun cuando la considera nominalmente como una "organización», hace de ella un tratamiento propio de una empresa mercantil66.

La cooperativa, para conseguir la socialización de la propiedad a que está llamada en Cuba, debe configurarse por el Derecho como un espacio asociativo, encaminado a la finalidad de satisfacción de las necesidades de sus asociados, que propicie el desarrollo efectivo de un proceso de producción - apropiación de bienes y servicios en el que prime la equidad, la voluntariedad y la autonomía en su constitución y funcionamiento, al interior de un clima institucional que guíe su contribución a la solución de los problemas económicos y culturales de la comunidad en que se desarrolla.

El reconocimiento de su particular naturaleza jurídica y el lugar que en ella corresponde al acto cooperativo, sentarían las bases para un tratamiento fiscal adecuado de las CNA.

Las bases constitucionales del régimen tributario en el país

La regulación en la Constitución de las bases del sistema tributario se considera un elemento esencial en su adecuado diseño y desarro-

65 Fernández, A.: Lecturas en pro del cooperativismo, ante las imprescindibles transformaciones económicas del socialismo cubano, Ed. Universo Sur, Cienfuegos, 2006, p. 27.

66 Vid. Ferro, L. I.: Las cooperativas de consumo. Presupuestos teóricos para su regulación jurídica en Cuba. Tesis en opción al título de Licenciado en Derecho, Universidad de Pinar del Río, Pinar del Río, 2016. 
llo. Como afirma Calvo Ortega, «La principal herramienta de transformación de lo que se puede llamar derecho tributario tradicional ha sido el establecimiento en las Constituciones de principios tributarios concretos» 67 .

Como mínimo, en la carta magna debe constitucionalizarse el deber de contribuir, dejando claramente definida la condición de contribuyentes. Esta regulación debe ir acompañada de la justicia tributaria, de manera que cualquier concepción y aplicación de los tributos deba efectuarse en virtud de los principios de capacidad contributiva, generalidad, y progresividad, y no de la confiscatoriedad. La previsión de tales principios obedece a la búsqueda de mayor justicia y equidad en la imposición de los tributos, lo cual repercute considerablemente «en la eliminación de cargas tributarias excesivas, en la disminución del fraude y la evasión fiscal, y por ende en el logro de los fines del sistema y la protección del contribuyente ${ }^{68}$.

También con rango constitucional pueden consagrarse las llamadas inmunidades tributarias, las cuales, a criterio de REYES y STANISLAO, son «aquellas situaciones en que disposiciones de orden constitucional impiden o prohíben la imposición, la tributación, o el gravamen respecto de determinados sujetos, bienes o actividades» ${ }^{69}$. Estas resultan de vital importancia para un grupo de sectores prioritarios de la economía de cualquier país, como suele ser el sector cooperativo. A tales previsiones de rango constitucional su jerarquía debe ofrecerles mayor seguridad y estabilidad jurídica, lo cual pasa por la eficacia de los mecanismos de control constitucional y aplicabilidad directa del texto fundamental, algo que también merece reforzarse en el caso cubano.

La posibilidad de realizar los ajustes antes aludidos se vislumbra próxima, pues - en el VII Congreso del Partido Comunista de Cuba de abril de 2016 - se expuso que la Constitución de la República será sometida a un proceso de reforma para «introducirle los ajustes pertinentes, luego de 40 años de vigencia, a tono con los cambios acaecidos en el plano internacional y las modificaciones resultantes del proceso de actualización del modelo económico y social» ${ }^{70}$.

67 Calvo, R.: «Hacia un nuevo derecho tributario», en Revista Foro, Nueva época, núm. 0, 2004, p. 61.

68 SIMÓN, L.: «Los principios de justicia tributaria en la historia constitucional cubana», en Cuestiones Constitucionales, núm. 25, julio-diciembre, 2011, p. 203.

69 ReYES, S. y StANISLAO, A.: El sistema tributario uruguayo y las cooperativas, consultado en http://www.aciamericas.coop/IMG/RTuruguay.pdf, en fecha 10 de abril de 2012.

70 Castro Ruz, R.: Discurso de clausura del VII Congreso del Partido Comunista de Cuba, consultado en www.cubadebate.cu, en fecha 12 de mayo de 2016. 
Armonización del tratamiento tributario y la relevancia social y económica de los contribuyentes

La política fiscal que condiciona la concepción que se tenga del sistema tributario, es una manifestación particular de la política general del Estado y, por ende, expresa las valoraciones que se hacen a lo interno de cada país en torno a los sectores, actores y actividades que deben disfrutar de estímulo, por su rol dentro del modelo político general que se procura implementar.

En consecuencia, en el caso cubano, convendría valorar, la entidad de los tipos impositivos aplicados a las CNA, en contraste con lo previsto para otros actores económicos. Nótese en este sentido que, por ejemplo, para las modalidades de la inversión extranjera se estableció un tipo impositivo del $15 \%$ para el impuesto sobre las utilidades, incluso llegando a exonerar al pago de este impuesto por ocho años a dichas modalidades. De ello que se deriva un tratamiento más beneficioso que el que se ha previsto para el sector cooperativo.

Este tratamiento fiscal de la inversión extranjera, puede entenderse de conformidad con el objetivo específico 1 del Eje Estratégico: Infraestructura, del Plan Nacional de Desarrollo Económico y Social hasta 2030, que se enfoca en "Generar un contexto macroeconómico y un marco institucional dirigido a impulsar los procesos inversionistas.... ${ }^{71}$.

No obstante, si se toma en cuenta que "Los tipos de cooperativas que reconoce el Modelo [Económico y Social Cubano de Desarro\|lo Socialista] forman parte del sistema de propiedad socialista», y que por ende se le considera «objeto de atención especial» 72 , resulta igualmente sensible el desarrollo del sector cooperativo, con el añadido de su valor social, al ya aludido valor económico. Por ende, sería pertinente considerar una mayor aproximación entre el tratamiento que se ofrece para el sector cooperativo y otros que como este se pretenden incentivar, por ejemplo el de la inversión extranjera.

En este mismo sentido, cabría plantearse continuar la tendencia establecida por la Disposición Final Quinta de la Ley 73/1994, que exoneraba del pago del Impuesto sobre Utilidades a las cooperativas de me-

71 VII Congreso del PCC: Plan Nacional de Desarrollo Económico y Social hasta 2030: propuesta de visión de la Nación, Ejes y Sectores Estratégicos, publicación en forma de tabloide, 2016.

72 Cfr. VII Congreso del PCC: Conceptualización del Modelo Económico y Social Cubano de Desarrollo Socialista, publicación en forma de tabloide, 2016. 
nores ingresos. Con ello solo se sería consecuente con el principio de justicia tributaria, sino además con la política de fomentar a la cooperativa como parte consustancial del modelo de socialismo cubano.

\section{A modo de conclusiones}

1. El acto cooperativo, en tanto responde al espíritu de servicio de la cooperativa para con sus asociados y no al ánimo de lucro, no crea base imponible. Tal premisa debe constituir el punto de partida en el régimen tributario de la institución, independientemente de otros beneficios fiscales que para su fomento puedan utilizarse con respecto a sus relaciones con terceros.

2. El régimen tributario de la cooperativa en Cuba durante las últimas décadas, en tanto formas de gestión colectivas y democráticas, las ha privilegiado con respecto a otros sujetos económicos, política que se ha acentuado con la actualización del modelo socioeconómico nacional a través de los beneficios ofrecidos a las CNA.

3. No obstante, este régimen es perfectible, para lo cual resulta pertinente una definición uniforme y acertada de su naturaleza jurídica; el reconocimiento y protección constitucional de sus bases generales; y la armonización del tratamiento tributario de la institución con la relevancia socioeconómica de los contribuyentes.

\section{Bibliografía}

Textos

1. BASTIDAS DELGADO, O.: iNo al impuesto sobre la renta a las cooperativas! Ellas deben considerarse como de no sujeción a impuestos. Caracas, 6 de enero de 2015, facilitado por el autor.

2. CALVO ORTEGA, R. 2004. "Hacia un nuevo derecho tributario», en Revista Foro, Nueva época, núm. 0.

3. CASTRO BORRERO, J.: Régimen Tributario del Sector Cooperativo, consultado en http://www.nuevalegislacion.com/index.php?option=com_conten t\&view=article\&catid=66:tributarios\&id=512:regimen-tributario-del-sector cooperativo\&ltemid=78, en fecha 10 de abril de 2012.

4. CASTRO RUZ, R.: Discurso de clausura del VII Congreso del Partido Comunista de Cuba, consultado en www.cubadebate.cu, en fecha 12 de mayo de 2016.

5. CRACOGNA, D. 1986. Estudios de Derecho Cooperativo, INTERCOOP Ed. Cooperativa Ltda., Buenos Aires. 
6. CRACOGNA, D. 1992. Problemas actuales del Derecho Cooperativo, INTERCOOP, Ed. Cooperativa Ltda., Buenos Aires.

7. COLECTIVO DE AUTORES. 2007. TEMAS DE DERECHO AGRARIO CUBANO, Tomo I, Ed. Félix Varela, La Habana.

8. FERNÁNDEZ PEISO, L.A. 2005. El fenómeno cooperativo y el modelo jurídico nacional. Propuesta para la nueva base jurídica del cooperativismo en Cuba, tesis presentada en opción al grado científico de Doctor en Ciencias Jurídicas, Cienfuegos.

9. FERNÁNDEZ PEISO, A. 2006. Lecturas en pro del cooperativismo, ante las imprescindibles transformaciones económicas del socialismo cubano, Ed. Universo Sur, Cienfuegos.

10. FERRO ÁlVAREZ, L. I. 2016. Las cooperativas de consumo. Presupuestos teóricos para su regulación jurídica en Cuba. Tesis en opción al título de Licenciado en Derecho, Universidad de Pinar del Río, Pinar del Río.

11. GARCÍA MÜLLER, A.: El acto cooperativo, construcción latinoamericana, recuperado de www.aidcmess.com.ar, el 12 de marzo de 2016.

12. GARCÍA MÜLLER, A.: Régimen Jurídico de la Empresa Cooperativa recuperado de www.aidcmess.com.ar, el 12 de marzo de 2016.

13. GARCÍA MÜLLER, A. 2014. Derecho Cooperativo y de la Economía Social y Solidaria, Tomo II Funcionamiento de la Empresa de Economía Social y Solidaria.

14. HERNÁNDEZ AGUILAR, O. 2015. "Algunas reflexiones en torno a la dimensión juridicoformal del proceso de constitución de cooperativas no agropecuaria en Cuba a partir del análisis del caso del municipio de Pinar del Río», en Boletín de la Asociación Internacional de Derecho Cooperativo, No. 49, Universidad de Deusto, pp. 279-306.

15. HERNÁNDEZ AGUILAR, O. 2015. «Las cooperativas no agropecuarias en Pinar del Río. Una aproximación al enfoque de género en su funcionamiento», en Deusto Estudios Cooperativos No. 6, Universidad de Deusto, pp. 159-179.

16. MARTíN HITA, L. 2014. "Las cooperativas no agropecuarias en Cuba», en REVESCO. Revista de Estudios Cooperativos, N. ${ }^{\circ} 115$.

17. MESA TEJEDA, N.T. 2014. "Reflexiones críticas en torno a la regulación de las cooperativas no agropecuaria en Cuba», en Boletín de la Asociación Internacional de Derecho Cooperativo, No. 48, Universidad de Deusto, pp. 227-243.

18. MOURA DE VICENTE, F. 2006. As Sociedades Cooperativas e o Regime Jurídico Tributáriode seusatos, Dissertação de Mestradoem Direito Cooperativo e Cidadania para a obténção do título de Mestreem Direito pela Universidade Federal do Paraná Programa de Pós-Graduação e Pesquisa da Faculdade de Direito, Curitiba.

19. NARANJO MENA, C: La naturaleza jurídica de la cooperativa y el acto cooperativo, SIBULE, Asesores Legales, 2014, recuperado de http://www. sibule.com/\#! La-Naturaleza-Jur\% C3\%ADdica-de-la-Cooperativa-y-elActo-Cooperativo/c104m/1, el 15 de mayo de 2016.

20. PASTORINO, R. 1981. Impuesto a las Transacciones Cooperativas, Ed. Intercoop, Buenos Aires. 
21. PÉREZ INCLÁN, C. 2007. Sistema Tributario Cubano, en COLECTIVO DE AUTORES: Apuntes de Derecho Financiero Cubano, Ed. Félix Varela, La Habana.

22. PIÑEIRO HARNECKER, C. (Compiladora). 2011. Cooperativas y Socialismo: Una mirada desde Cuba, Ed. Caminos, La Habana.

23. PIÑEIRO HARNECKER, C.: «Diagnóstico preliminar de las cooperativas no agropecuarias en La Habana», Cuba, mayo de 2014.

24. REYES LAVEGA, S. y STANISLAO LAMENTA, A.: El sistema tributario uruguayo y las cooperativas, consultado en http://www.aciamericas.coop/ IMG/RTuruguay.pdf, en fecha 10 de abril de 2012.

25. RODRíGUEZ MUSA, O. 2011. La cooperativa como figura jurídica. Perspectivas constitucionales en Cuba para su aprovechamiento en otros sectores de la economía nacional diferentes al agropecuario, Ed. DYKINSON, S.L. Madrid.

26. RODRÍGUEZ MUSA, O. 2013. «La autonomía cooperativa y su expresión jurídica. Una aproximación crítica a su actual implementación legal en Cuba» en Boletín de la Asociación Internacional de Derecho Cooperativo, No. 47, Bilbao, pp. 129-155.

27. RODRÍGUEZ MUSA, O. y HERNÁNDEZ AGUILAR, O. 2015. «Las limitaciones jurídicas de la cooperativa en el socialismo. Perspectivas para el perfeccionamiento de su regulación en Cuba». REVESCO. Revista de Estudios Cooperativos, No. 117, pp. 99-124.

28. SALINAS PUENTE, A. 1954. Derecho Cooperativo, Ed. Cooperativismo, México.

29. SILI, M., SANGUINETTI, J. y MEILLER, A., 2014. «El cooperativismo agrario y su contribución al desarrollo rural. La experiencia de la Unión Agrícola de Avellaneda, Argentina». CIRIEC-España, Revista de Economía Pública, Social y Cooperativa, No. 82, pp. 155-178.

30. SIMÓN OTERO, L. 2011. "Los principios de justicia tributaria en la historia constitucional cubana», en Cuestiones Constitucionales, núm. 25, julio-diciembre, p. 203.

31. SIMÓN OTERO, L. 2014. "Comentarios a la nueva ley tributaria cubana», en Documentos. No. 10, Instituto de Estudios Fiscales.

32. TORGA HERNÁNDEZ, N. y RODRÍGUEZ MUSA, O. 2014. "La cooperativa de segundo grado: perspectivas para su desarrollo en Cuba» en Boletín de la Asociación Internacional de Derecho Cooperativo, No. 48, Bilbao, pp. 81-102.

33. TORRES MORALES, C: Reconocimiento del acto cooperativo en la legislación peruana, recuperado de http://www.teleley.com/articulos/ art_221013a.pdf, el 15 de mayo de 2016.

34. TORRES MORALES, C: ¿Por qué no debe derogarse la Ley 29683 y la Ley 29717, recuperado de www.aidcmess.com.ar, el 12 de marzo de 2016.

35. TORRES, C. 1983. El Cooperativismo: el modelo alternativo. Universidad de Lima. Lima. 
36. TORRES MORALES, C: «Reconocimiento del acto cooperativo en la legislación peruana», consultado en http://www.teleley.com/articulos/ art_221013a.pdf, el 15 de mayo de 2016.

37. TRISTÁ ARBEZÚ, G.: Cooperativas no Agropecuarias, Comisión de Implementación de los Lineamientos, Conferencia ofrecida en septiembre de 2015.

38. VALDÉS LOBÁN, E. 2002. La Imposición sobre el Consumo en Cuba. Valoración crítica y propuesta de reforma, Ed. Publicaciones de la Universidad de Alicante, España.

39. VUOTTO, M. 2016. "Las cooperativas no agropecuarias y la transformación económica en Cuba: políticas, procesos y estrategias». REVESCO. Revista de Estudios Cooperativos, No. 120, pp. 149-181.

\section{Documentos}

1. ACl-AMÉRICAS: Ley Marco para las Cooperativas de América Latina, San José, 2008, en www.aciamericas.coop, consultada 18 de diciembre de 2009.

2. VI CONGRESO DEL PARTIDO COMUNISTA DE CUBA: Lineamientos de la Política Económica y Social del Partido y la Revolución. La Habana. 2012.

3. VII CONGRESO DEL PARTIDO COMUNISTA DE CUBA: Conceptualización del Modelo Económico y Social Cubano de Desarrollo Socialista, publicación en forma de tabloide, 2016.

4. VII CONGRESO DEL PARTIDO COMUNISTA DE CUBA: Plan Nacional de Desarrollo Económico y Social hasta 2030: propuesta de visión de la Nación, Ejes y Sectores Estratégicos, publicación en forma de tabloide, 2016.

\section{Legislación}

1. Constitución de la República de Cuba. Gaceta Oficial de la República de Cuba. Edición Especial de 24 de febrero de 1976.

2. Constitución de la República de Cuba, reformada por la Ley de Reforma Constitucional. Gaceta Oficial de la República de Cuba N. 9 Extraordinaria de 13 de julio de 1992.

3. Constitución de la República de Cuba, reformada por la Ley de Reforma Constitucional. Gaceta Oficial de la República de Cuba N. ${ }^{\circ} 10$ Extraordinaria de 16 de julio de 2002.

4. Código Civil. Ley No. 59 de 16 de julio de 1987 (actualizado). Ministerio de Justicia, La Habana, 1998.

5. Ley 73. Del Sistema Tributario. Gaceta Oficial de la República de Cuba N. 8 Extraordinaria de 5 de agosto de 1994.

6. Ley No. 95. Ley de Cooperativas de Producción Agropecuaria y de Créditos y Servicios. Gaceta Oficial Ordinaria de 29 de noviembre de 2002. 
7. Ley No. 113. Del Sistema Tributario. Gaceta Oficial No. 053 de 21 de noviembre de 2012.

8. Ley No. 118. Ley de la Inversión Extranjera. Gaceta Oficial No. 20 Extraordinaria de 16 de abril de 2014.

9. Ley No. 116. Código de Trabajo. Gaceta Oficial No. 29 Extraordinaria de 17 de junio de 2014.

10. Decreto-Ley No. 305. De las Cooperativas No Agropecuarias. Gaceta Oficial No. 53 Extraordinaria de 11 de diciembre de 2012.

11. Decreto-Ley No. 306. Del régimen especial de seguridad social de los socios de las cooperativas no agropecuarias. Gaceta Oficial No. 53 Extraordinaria de 11 de diciembre de 2012.

12. Decreto No. 309. Reglamento de las Cooperativas No Agropecuarias. Gaceta Oficial No. 53 Extraordinaria de 11 de diciembre de 2012.

13. Resolución No. 574 de 13 de agosto de 2012 del Ministerio de la Agricultura. Reglamento General de las Unidades Básicas de Producción Cooperativa. Disponible en Ministerio de la Agricultura (2012). Compendio de Documentos sobre las UBPC. La Habana.

14. Resolución No. 427 del Ministerio de Finanzas y Precios, Gaceta Oficial N. ${ }^{\circ} 053$ Extraordinaria de 11 de diciembre de 2012, MINJUS, La Habana, 2012.

15. Resolución 124 del Ministerio de Finanzas y Precio. Gaceta Oficial N. ${ }^{\circ} 12$ Extraordinaria de 13 de abril de 2016, MINJUS, La Habana, 2016. 


\section{Derechos de autor}

El Boletín de la Asociación Internacional de Derecho Cooperativo es una revista de acceso abierto lo que significa que es de libre acceso en su integridad inmediatamente después de la publicación de cada número. Se permite su lectura, la búsqueda, descarga, distribución y reutilización legal en cualquier tipo de soporte sólo para fines no comerciales y según lo previsto por la ley; sin la previa autorización de la Editorial (Universidad de Deusto) o el autor, siempre que la obra original sea debidamente citada (número, año, páginas y DOI si procede) y cualquier cambio en el original esté claramente indicado.

\section{Copyright}

The International Association of Cooperative Law Journal is an Open Access journal which means that it is free for full and immediate access, reading, search, download, distribution, and lawful reuse in any medium only for non-commercial purposes, without prior permission from the Publisher or the author; provided the original work is properly cited and any changes to the original are clearly indicated. 